\title{
EPIDEMIOLOGY AND EVIDENCE-BASED \\ MANAGEMENT OF COMMON BEHAVIOURAL AND EMOTIONAL DISORDERS IN CHILDHOOD
}

Michael O. Ogundele

\section{Background}

There are several types of emotional and behavioural disorders (EBD) in children classified as either internalizing and externalizing problems (Fig 1).

They include challenging and aggressive behaviours, Disruptive behaviour Disorders Emotional problems and Autistic disorders.

\section{Prevalence}

EBD are also classified as Mental Health disorders affecting up to $20.9 \%$ of children and youth, up to age 17 years.

Low-intensity naughty, defiant and impulsive behaviour from time to time, is normal, but children with extremely difficult and challenging behaviours outside the norm for the age, are regarded as having behaviour disorders.

\section{Management}

Holistic management strategies require multi-disciplinarian approach including various combinations of child- and family-focused psychological therapies including CBT, behavioural modification and social communication enhancement techniques, and parenting skills training.

It requires integrated multi-level and multi-disciplinarian approach including Psychologists, Psychiatrists, Behavioural Analysts, Nurses, Social care staff, Speech and language therapists, Educational staff, Occupational therapists, Physiotherapists, Paediatricians and Pharmacists.

Effective alternative educational procedures also need to be implemented for the school age children and adolescents. Use of antipsychotic medications may be considered only in combination with psychological and other environmental interventions.

\section{Conclusion}

It is important for all healthcare professionals, especially the Paediatricians to be aware of the range of presentation, prevention and management of the problematic behaviours and emotional disorders in children and adolescents.

Childhood EBDs, if left untreated, may have negative short-term and long-term effects on an individual's personal, educational, family and later professional life.

Figure 1 showing the classification of common childhood EBD

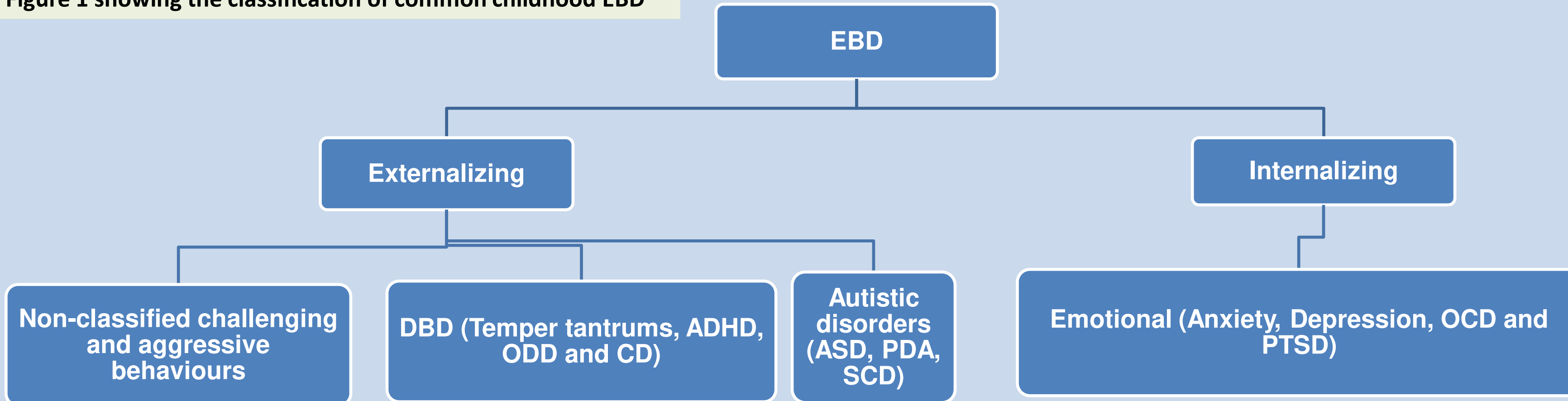

